\title{
Zinc Oxide-Catalyzed Dehydrogenation of Primary Alcohols into Carboxylic Acids
}

\author{
Monda, Fabrizio; Madsen, Robert
}

Published in:

Chemistry - A European Journal

Link to article, DOI:

10.1002/chem.201804402

Publication date:

2018

Document Version

Peer reviewed version

Link back to DTU Orbit

Citation (APA):

Monda, F., \& Madsen, R. (2018). Zinc Oxide-Catalyzed Dehydrogenation of Primary Alcohols into Carboxylic Acids. Chemistry - A European Journal, 24(67), 17832-17837. https://doi.org/10.1002/chem.201804402

\section{General rights}

Copyright and moral rights for the publications made accessible in the public portal are retained by the authors and/or other copyright owners and it is a condition of accessing publications that users recognise and abide by the legal requirements associated with these rights.

- Users may download and print one copy of any publication from the public portal for the purpose of private study or research.

- You may not further distribute the material or use it for any profit-making activity or commercial gain

- You may freely distribute the URL identifying the publication in the public portal

If you believe that this document breaches copyright please contact us providing details, and we will remove access to the work immediately and investigate your claim. 


\title{
Zinc Oxide-Catalyzed Dehydrogenation of Primary Alcohols into Carboxylic Acids
}

\author{
Fabrizio Monda and Robert Madsen*[a]
}

\begin{abstract}
Zinc oxide has been developed as a catalyst for the dehydrogenation of primary alcohols into carboxylic acids and hydrogen gas. The reaction is performed in mesitylene solution in the presence of potassium hydroxide followed by workup with hydrochloric acid. The transformation can be applied to both benzylic and aliphatic primary alcohols and the catalytically active species was shown to be a homogeneous compound by a hot filtration test. Dialkylzinc and strongly basic zinc salts also catalyze the dehydrogenation with similar results. The mechanism is believed to involve the formation of a zinc alkoxide which degrades into the aldehyde and a zinc hydride. The latter reacts with the alcohol to form hydrogen gas and regenerating the zinc alkoxide. The degradation of a zinc alkoxide into the aldehyde upon heating was confirmed experimentally. The aldehyde can then undergo a Cannizzaro reaction or a Tishchenko reaction which in the presence of hydroxide leads to the carboxylic acid.
\end{abstract}

\section{Introduction}

The acceptorless dehydrogenation of alcohols has gained much attention for the synthesis of imines, esters, amides, carboxylic acids, heterocycles and aldol products. ${ }^{[1]}$ The reactions only produce hydrogen gas as a co-product and does not require any stoichiometric oxidants. The most widely used catalysts have been complexes based on the platinum group metals such as ruthenium and iridium. ${ }^{[1]}$ More recently, different iron, cobalt and manganese complexes have also been shown to catalyze the dehydrogenations. ${ }^{[2]}$ In addition, nickel, copper and molybdenum catalysts have been employed in several special cases. ${ }^{[3]}$ Zinc, however, has gained very little interest for catalyzing the acceptorless dehydrogenation of alcohols.

Due to its poor redox properties zinc catalysis is often viewed as being limited to Lewis acid mediated reactions. Zinc exists in oxidation states 0 and +2 and only in the latter is it possible to form complexes with ligands. However, in recent years an increasing number of zinc(II)-catalyzed oxidations with hydroperoxides and reductions with hydride sources have been developed. ${ }^{[4]}$ The last category includes hydrosilylation of ketones, esters, imides and amides with silanes ${ }^{[5]}$ as well as hydrogenation of ketones and imines with hydrogen gas. ${ }^{[6]}$ Most of the transformations are believed to proceed through the

[a] F. Monda, Prof. Dr. R. Madsen Department of Chemistry Technical University of Denmark 2800 Kgs. Lyngby (Denmark) E-mail: rm@kemi.dtu.dk

Supporting information for this article is given via a link at the end of the document. formation of zinc(II) hydrides ${ }^{[7]}$ which are known to be able to reduce $\mathrm{C}=\mathrm{O}$ and $\mathrm{C}=\mathrm{N}$ bonds.

A few dehydrogenations with the release of hydrogen gas have also been described with zinc(II) catalysts. Zinc triflate catalyzes the borylation and silylation of terminal alkynes with boranes and silanes, ${ }^{\left[{ }^{[8]}\right.}$ respectively, as well as the $\mathrm{N}$-silylation of indoles with silanes. ${ }^{[9]}$ Zinc oxide catalyzes the dehydrogenation of alcohols in the gas phase at temperatures around $400{ }^{\circ} \mathrm{C}$ and the reaction is often accompanied by a competing dehydration reaction. ${ }^{[10]}$ In addition, heating a mixture of a primary alcohol, a zinc salt and sodium hydroxide to $210-260{ }^{\circ} \mathrm{C}$ under neat conditions has been reported to afford a mixture of the corresponding ester and carboxylic acid in moderate yields. ${ }^{[11]}$ The transformation is believed to proceed through a Tishchenko reaction $^{[12]}$ of the intermediate aldehyde to give the ester. Thus, it appears that zinc(II) species are able to mediate the necessary molecular pathways for releasing hydrogen gas and it is therefore conceivable that they will also catalyze alcohol dehydrogenations at more moderate temperatures in solution.

Herein, we describe the development of a zinc(II)-catalyzed protocol for the dehydrogenation of primary alcohols into carboxylic acids. Zinc oxide was shown to be the preferred catalyst and with a price of only $\$ 1 / \mathrm{kg}$ it constitutes by far the most inexpensive catalyst for alcohol dehydrogenation in solution. ${ }^{[1-3]}$ The acceptorless dehydrogenative synthesis of carboxylic acids from alcohols has previously been described with a $0.1-5 \%$ loading of ruthenium, ${ }^{[13]}$ iridium,,${ }^{[14]}$ palladium, ${ }^{[15]}$ rhodium, ${ }^{[16]}$ silver ${ }^{[17]}$ and nicke[ ${ }^{[18]}$ catalysts at reflux temperature in water, toluene or mesitylene solution. The dehydrogenative protocol constitutes a benign alternative to alcohol oxidation to carboxylic acid which is usually performed with a stoichiometric metal oxide or by a catalytic procedure with a stoichiometric cooxidant. ${ }^{[19]}$

\section{Results and Discussion}

The transformation was discovered while attempting to use zinc metal as a reducing agent for other Earth-abundant metals in the presence of water and hydroxide. We have previously performed a dehydrogenative self-condensation of 1-phenylethanol into 3methyl-1,3-diphenylpropan-1-one with a ruthenium catalyst. ${ }^{[20]}$ The reaction is carried out at reflux temperature with one equiv. of potassium hydroxide. Several inexpensive metals ${ }^{[2]}$ were investigated as new catalysts for this transformation with different ligands and zinc metal as a reducing agent. However, it was quickly realized that zinc was responsible for the conversion into the product. In fact, reacting the alcohol with 0.25 equiv. of $\mathrm{Zn}$ in mesitylene solution gave $45 \%$ yield of the ketone product with some unreacted alcohol remaining (Scheme 1). Zinc metal is known to react with water in organic solvents and produce 
zinc oxide upon heating. ${ }^{[21]}$ Therefore, we speculated that the actual catalyst was zinc oxide which was confirmed by repeating the reaction with this salt to give the ketone in $49 \%$ yield. Again, unreacted alcohol was responsible for the moderate yield and it was not possible to further optimize the reaction. Instead, it was decided to investigate the transformation with a primary alcohol which would presumably be more reactive.<smiles>CC(O)c1ccccc1</smiles>

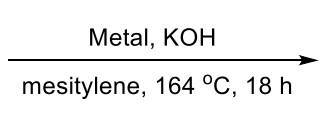

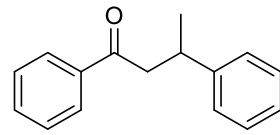

Metal $=\mathrm{Zn}: 45 \%$ yield Metal $=\mathrm{ZnO}: 49 \%$ yield
Scheme 1. ZnO-catalyzed self-condensation of 1-phenylethanol.

Indeed, reacting benzyl alcohol with $10 \%$ of zinc oxide and one equiv. of potassium hydroxide in refluxing mesitylene now furnished the carboxylic acid in 58\% isolated yield after workup by acidification (Table 1, entry 1). However, full conversion of the alcohol was still not obtained and a number of experiments were therefore performed to improve the transformation. Replacing zinc oxide with zinc metal gave a very similar outcome (entry 2) while poor results were obtained with lithium hydroxide and sodium hydroxide as the base (entries 3 and 4). Additives also gave a lower yield (entries 5 and 6) while the reaction with $p$-cymene as the solvent furnished the acid in $73 \%$ yield (entry 7 ). The improved yield in the latter case is most likely due to the higher reaction temperature since no conversion of the alcohol was obtained upon refluxing the reactants in toluene or diglyme. As a result, it was decided to continue the optimization in mesitylene solution.

Several other zinc sources were also investigated and interestingly $\mathrm{Et}_{2} \mathrm{Zn}, \mathrm{Me}_{2} \mathrm{Zn}, \mathrm{Zn}(\mathrm{HMDS})_{2}$ and $\mathrm{Zn}(\mathrm{OMe})_{2}$ all gave yields similar to zinc oxide and with a slightly higher alcohol conversion (entries 8-11). This indicates that the catalytically active species is the same in all cases regardless of the zinc source. Therefore, the optimization continued with the inexpensive zinc oxide catalyst. The morphology of this oxide had no influence on the outcome, but when a zinc oxide dispersion in water was employed, the reaction stalled (entry 12). This could suggest that water had a detrimental influence on the dehydrogenation and explain the cumbersome reaction in Scheme 1 where water is formed as a byproduct. In fact, commercial samples of potassium hydroxide contains 0.35 0.55 equiv. of water per equiv. of hydroxide and a new protocol was therefore devised to decrease the amount of water in the reaction. First, potassium hydroxide was mixed with zinc oxide and the mixture heated to $170{ }^{\circ} \mathrm{C}$ under vacuum for $1 \mathrm{~h}$. This produced a molten slurry to which benzyl alcohol and mesitylene were added. After stirring the mixture at reflux for $18 \mathrm{~h}$ the acid was now isolated in $72 \%$ yield with an improved conversion of the alcohol (entry 13). To ensure complete conversion of benzyl alcohol, the amounts of zinc oxide and potassium hydroxide were increased to $20 \%$ and 2 equiv., respectively, which now afforded $91 \%$ yield of benzoic acid (entry 14). Notably, essentially the same yield was obtained with $20 \%$ of $\mathrm{Zn}(\mathrm{OMe})_{2}$ (entry 15). Control experiments revealed that zinc oxide and potassium hydroxide were both vital for the transformation (entries 16 and 17). Thus, an optimized protocol has been developed for the acceptorless dehydrogenation of alcohols into carboxylic acids by using zinc oxide and potassium hydroxide in refluxing mesitylene (entry 14 ).

Table 1. Optimization of zinc-catalyzed dehydrogenation. ${ }^{[a]}$

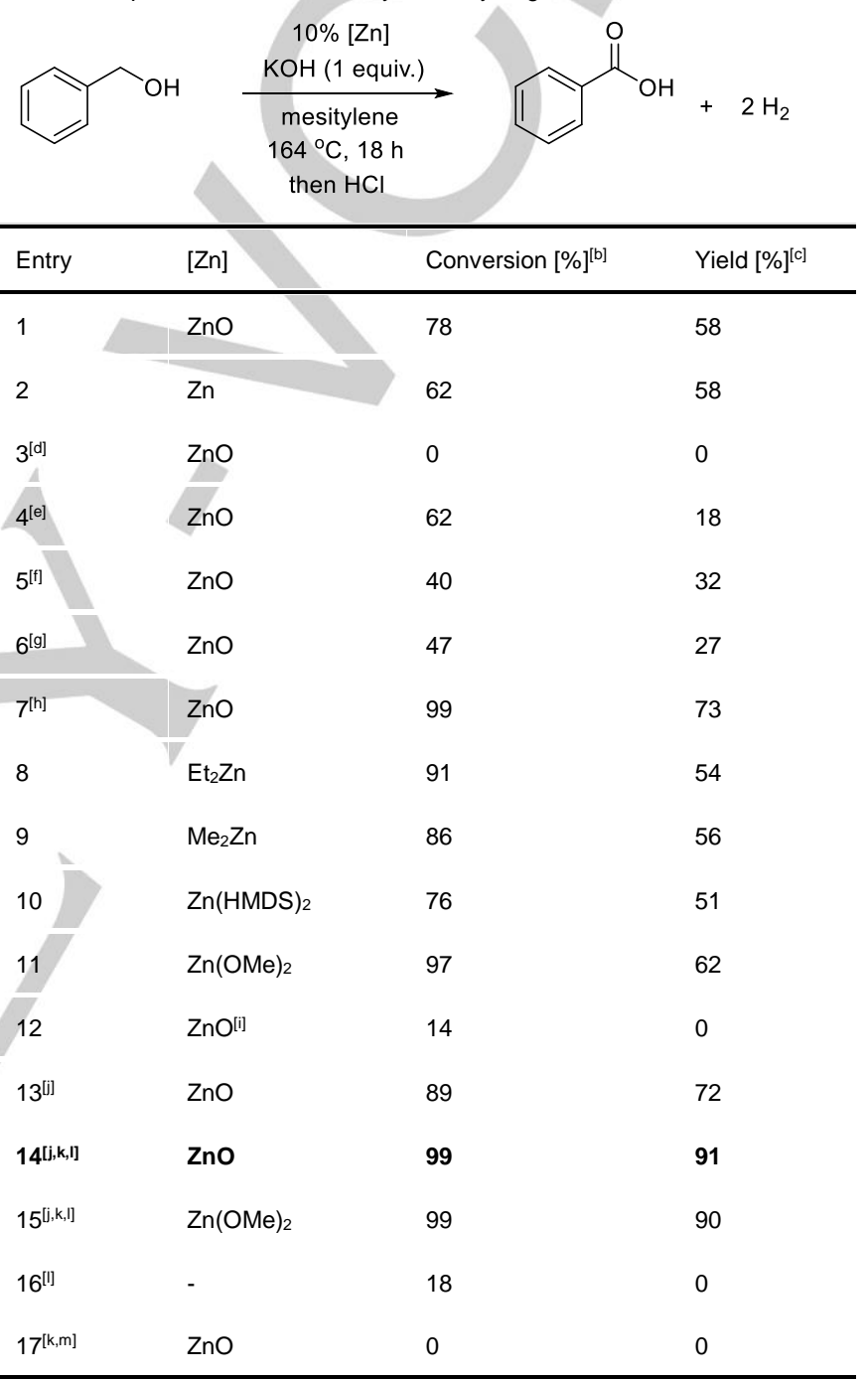

[a] Reaction conditions: Benzyl alcohol (2 mmol), [Zn] (0.2 mmol), $\mathrm{KOH}(2$ $\mathrm{mmol})$, mesitylene (3 $\mathrm{mL})$, reflux, $18 \mathrm{~h}$. [b] Determined by GC. [c] Isolated yield. [d] With $\mathrm{LiOH}$ instead of $\mathrm{KOH}$. [e] With $\mathrm{NaOH}$ instead of $\mathrm{KOH}$. [f] With 1 equiv. of $\mathrm{LiCl}$ as additive. [g] With 1 equiv. of $\mathrm{KF}$ as additive. [h] In $p$ cymene at $177^{\circ} \mathrm{C}$. [i] 20 wt.\% dispersion in water. [j] [Zn] and $\mathrm{KOH}$ premixed at $170{ }^{\circ} \mathrm{C}$ for $1 \mathrm{~h}$. [k] With $20 \%$ of [Zn]. [l] With 2. equiv. of $\mathrm{KOH}$. [m] Without $\mathrm{KOH}$.

The procedure was now applied to a variety of primary alcohols to explore the substrate scope and limitations of the reaction. First, several other benzylic alcohols were subjected to the dehydrogenation (Table 2). p-Methylbenzyl alcohol afforded $p$-toluic acid in $85 \%$ isolated yield (entry 1 ) while the $p$-methoxy 
analogue gave $p$-anisic acid in $79 \%$ yield (entry 2 ). Almost the same outcome was obtained with $p$-methylthiobenzyl alcohol illustrating the compatibility of a thio ether with the transformation (entry 3). p-Phenyl- and p-benzyloxybenzyl alcohol furnished the corresponding acids in 62 and $91 \%$ yield, respectively (entries 4 and 5 ). When $p$-chlorobenzyl alcohol was submitted to the optimized conditions complete dechlorination occurred and benzoic acid was isolated in $76 \%$ yield (entry 6 ). To prevent the dehalogenation the reaction temperature was lowered to $150{ }^{\circ} \mathrm{C}$ which now allowed $p$-chlorobenzoic acid to be isolated in $47 \%$ yield (entry 7 ). p-Bromobenzyl alcohol also underwent complete dehalogenation in refluxing mesitylene, but at $150{ }^{\circ} \mathrm{C} p$-bromobenzoic acid could be obtained in $42 \%$ yield (entry 8). The naphthalene substrate 2-naphthylmethanol afforded the corresponding 2-naphthoic acid in $70 \%$ yield (entry 9). 2,4,6-Trimethylbenzyl alcohol, on the other hand, did not react in the transformation (result not shown) illustrating the steric effect of the two ortho methyl groups.

Table 2. Zinc-catalyzed dehydrogenation of benzylic alcohols. ${ }^{[a]}$

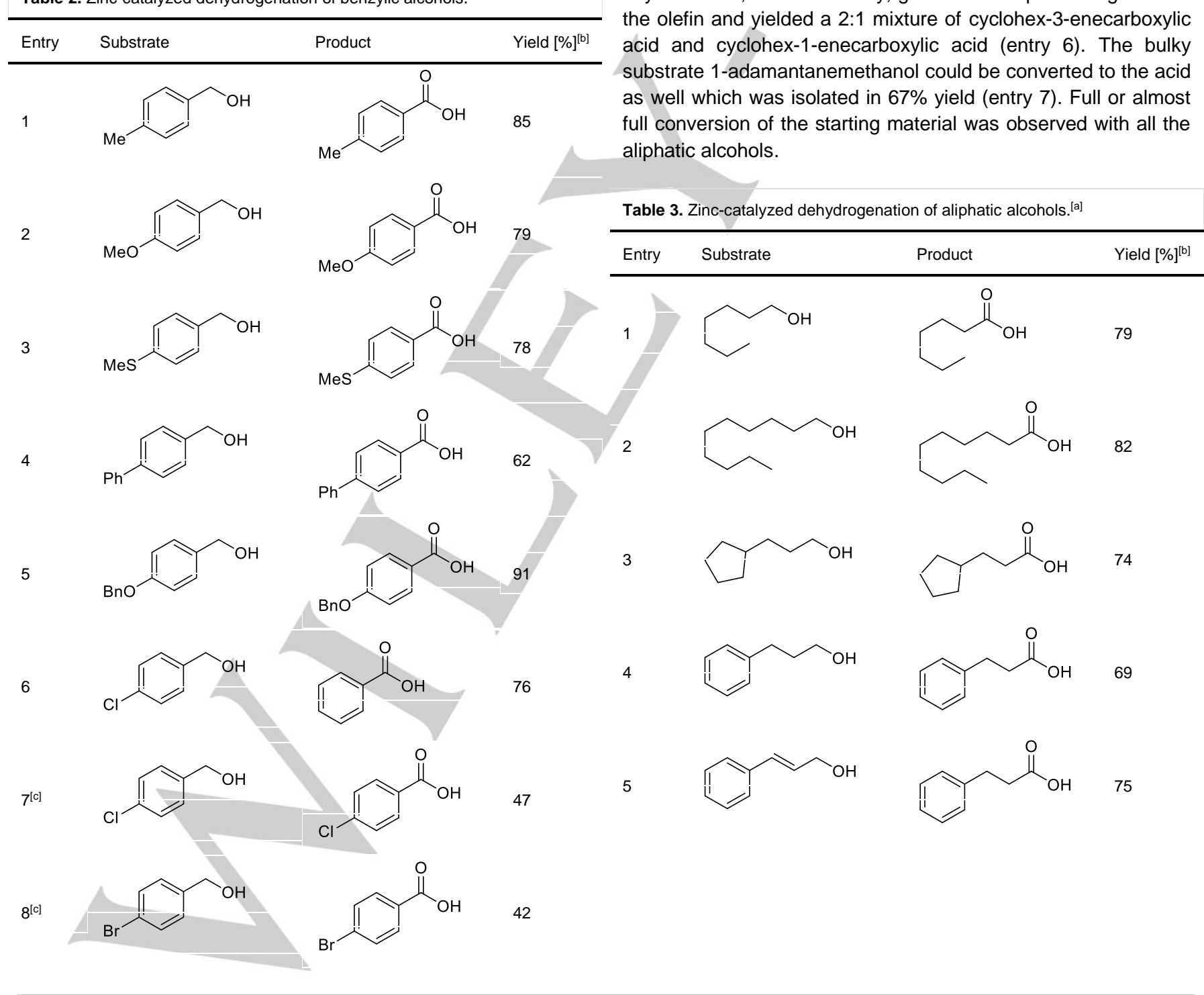

9<smiles>OCc1ccc2ccccc2c1</smiles><smiles>O=C(O)c1ccc2ccccc2c1</smiles>

70

[a] Reaction conditions: $\mathrm{ZnO}(0.4 \mathrm{mmol})$ and $\mathrm{KOH}(4 \mathrm{mmol})$ at $170{ }^{\circ} \mathrm{C}$ for $1 \mathrm{~h}$ then add benzylic alcohol $(2 \mathrm{mmol})$ and mesitylene $(3 \mathrm{~mL})$ and heat to $164{ }^{\circ} \mathrm{C}$ for $18 \mathrm{~h}$. [b] Isolated yield. [c] Reaction temperature $150{ }^{\circ} \mathrm{C}$.

The transformation could also be applied to aliphatic primary alcohols although a slower conversion was observed and a longer reaction time of $36 \mathrm{~h}$ was necessary (Table 3 ). Under these conditions, heptan-1-ol and decan-1-ol afforded the corresponding acids in 79 and $82 \%$ yield, respectively (entries 1 and 2). 3-Cyclopentyl- and 3-phenylpropan-1-ol gave the 3substituted propanoic acids in 74 and $69 \%$ yield (entries 3 and 4). Cinnamyl alcohol also furnished 3-phenylpropanoic acid due to a simultaneous reduction of the olefin (entry 5). Cyclohex-3enylmethanol, on the contrary, gave rise to a partial migration of the olefin and yielded a 2:1 mixture of cyclohex-3-enecarboxylic acid and cyclohex-1-enecarboxylic acid (entry 6). The bulky substrate 1-adamantanemethanol could be converted to the acid h all the

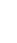

\section{.}

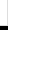



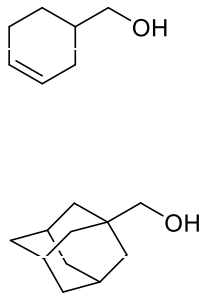
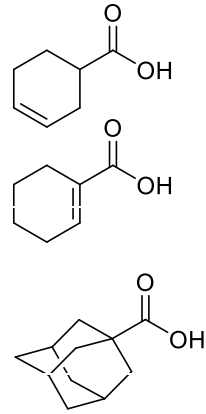

$78^{[\mathrm{c}]}$

67

[a] Reaction conditions: $\mathrm{ZnO}(0.4 \mathrm{mmol})$ and $\mathrm{KOH}(4 \mathrm{mmol})$ at $170{ }^{\circ} \mathrm{C}$ for $1 \mathrm{~h}$ then add aliphatic alcohol $(2 \mathrm{mmol})$ and mesitylene $(3 \mathrm{~mL})$ and heat to $164{ }^{\circ} \mathrm{C}$ for 36 h. [b] Isolated yield. [c] Isolated as a 2:1 mixture of cyclohex-3-ene- and cyclohex-1-enecarboxylic acid.

If the amount of potassium hydroxide was lowered, the aliphatic alcohols produced a mixture of the carboxylic acid and the corresponding Guerbet alcohol ${ }^{22}$ (by self-coupling through an aldol pathway). As an example, heptan-1-ol furnished $51 \%$ of heptanoic acid and $46 \%$ of the Guerbet alcohol (2-pentylnonan1 -ol) with one equiv. of potassium hydroxide while the yields were $6 \%$ and $50 \%$, respectively, with $30 \%$ of the base. The formation of heptanoic acid is due to a faster dehydrogenation of heptan-1-ol than of the more hindered Guerbet alcohol. However, it was never possible to optimize the Guerbet coupling to give more than a moderate yield and this reaction was therefore not further developed.

The evolution of hydrogen gas was measured from the reaction with zinc oxide in $p$-cymene (Table 1 , entry 7 ). A total of $61 \mathrm{~mL}(2.5 \mathrm{mmol})$ was collected corresponding to approximately 2 equiv. of gas in a reaction with an yield of $73 \%$. The gas was shown to be $\mathrm{H}_{2}$ which confirms that the transformation takes place by an acceptorless dehydrogenative pathway. Interestingly, the measurement showed that the reaction had almost gone to completion after about $6 \mathrm{~h}$ (Figure 1)

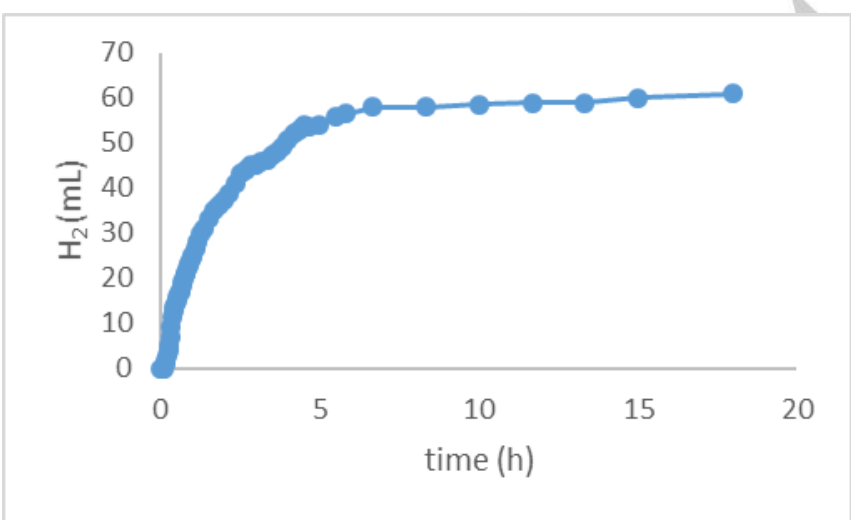

Figure 1. Development of hydrogen gas over time. Conditions: $\mathrm{BnOH}(1$ $\mathrm{mmol}), \mathrm{ZnO}(0.2 \mathrm{mmol}), \mathrm{KOH}(2 \mathrm{mmol}), p$-cymene $(3 \mathrm{~mL}), 177^{\circ} \mathrm{C}$

Zinc oxide was submitted to trace metal analysis by inductively coupled plasma mass spectrometry (ICP-MS) to exclude other elements known to perform alcohol dehydrogenation. ${ }^{[23]}$ Fortunately, none of these metals were observed beyond their detection limits of typically $1 \mathrm{ppm}$ and the transformation is therefore not believed to be catalyzed by trace metal residues in zinc oxide.

The catalytically active species is not known and several experiments were performed in order to gain more information about the actual catalyst. First, the reaction in Table 1, entry 14 was repeated with $50 \mu \mathrm{L}$ of mercury added from the beginning or after 2, 4 or $6 \mathrm{~h}$. None of these mercury poisoning experiments had any significant influence on the yield of benzoic acid and zinc nanoparticles can therefore be excluded as the actual catalyst. ${ }^{[17]}$

Next, it was decided to perform a hot filtration test since the reaction mixture of zinc oxide and potassium hydroxide is heterogeneous, but the actual catalyst could be a homogeneous species. Thus, an experiment was performed as in Table 1 , entry 1 , but after 35 min with about $15-20 \%$ alcohol conversion the mixture was filtered through a nylon syringe filter $(0.22 \mu \mathrm{m}$ pore size) to afford a clear filtrate. This solution was then refluxed for an additional $18 \mathrm{~h}$ to give $59 \%$ alcohol conversion and $45 \%$ yield of benzoic acid. This result indicates that a homogeneous species is formed and is responsible for the catalytic conversion. Accordingly, it is unlikely that the transformation takes place on the surface of zinc oxide as has been proposed in the gas phase dehydrogenation based on kinetic and spectroscopic measurements. ${ }^{[24]}$ A control experiment was performed where zinc oxide and potassium hydroxide were refluxed in mesitylene for $35 \mathrm{~min}$ (without adding the alcohol) and then subjected to the same hot filtration. The alcohol was then added to the clear filtrate and the solution refluxed for $18 \mathrm{~h}$. This second hot filtration experiment gave no conversion of the alcohol at all which shows that the alcohol is involved in the formation of the homogeneous species and this cannot alone be formed from zinc oxide and potassium hydroxide.

As a result, the homogeneous species is most likely a zinc alkoxide which would also explain why the transformation can be catalyzed by a variety of other zinc(II) species to give similar results as with zinc oxide. There is to the best of our knowledge no evidence in the literature for a classical $\beta$-hydride elimination pathway with zinc alkoxides to form zinc hydrides. ${ }^{[25]}$ The enzyme alcohol dehydrogenase reacts by hydride elimination from a zinc alkoxide, but the hydride is transferred to NAD+. ${ }^{[26]}$ This, however, does not rule out that a zinc hydride can be formed at elevated temperature and especially if the carbonyl compound is removed from the mixture. An experiment was therefore conducted where $48 \mathrm{mmol}$ of benzyl alcohol was reacted with $6 \mathrm{mmol}$ of $\mathrm{Et}_{2} \mathrm{Zn}$ at $0{ }^{\circ} \mathrm{C}$ under an inert atmosphere. The mixture was then slowly heated to $185^{\circ} \mathrm{C}$ over $15 \mathrm{~h}$ with a distillation head attached. During this time, $4 \mathrm{mmol}$ of a $5: 3$ mixture of benzyl alcohol and benzaldehyde distilled off from the reaction. This experiment shows that a zinc alkoxide can in fact be decomposed to form the aldehyde (and most likely the corresponding zinc hydride). A very interesting observation was 
made when the residue from the distillation was analyzed by NMR. This showed a 1:1 mixture of benzyl alcohol and benzyl benzoate showing that a large amount of benzaldehyde was actually formed in the experiment, but had reacted further to the ester through a Tishchenko reaction. A recent study showed that zinc metal catalyzes the Tishchenko reaction where zinc alkoxides are believed to be the active catalyst formed in situ. ${ }^{[27]}$

Consequently, we consider the most likely mechanism to involve a zinc alkoxide and a zinc hydride (Scheme 2). The zinc alkoxide is first generated from zinc oxide and the alcohol and then degrades into the aldehyde and the zinc hydride. The latter deprotonates the alcohol to regenerate the alkoxide in a reaction that is known to occur readily. ${ }^{[28]}$ The exact pathway for the conversion of the zinc alkoxide in to the zinc hydride can only be speculated upon. The classical $\beta$-hydride elimination is one possibility if $X$ in Scheme 2 is a vacant coordination site. Another possibility is an outer-sphere bifunctional pathway if $X$ is an alcohol. $\left.\left[\left(\mathrm{HOCH}_{2} \mathrm{Ph}\right) \mathrm{Zn}-\mathrm{OCH}_{2} \mathrm{Ph}\right)\right]$ would then be cleaved into [ $\left(\mathrm{PhCH}_{2} \mathrm{O} \cdots \mathrm{HOCH}_{2} \mathrm{Ph}\right) \mathrm{Zn}$ ] followed by transfer of the benzylic hydride to the metal through a six-membered transition state. This bifunctional pathway has been calculated for hydride eliminations in $\mathrm{NH}$-metal-alkoxide complexes of osmium, ruthenium and iron ${ }^{[29]}$ as well as for the Shvo catalyst. ${ }^{[30]}$

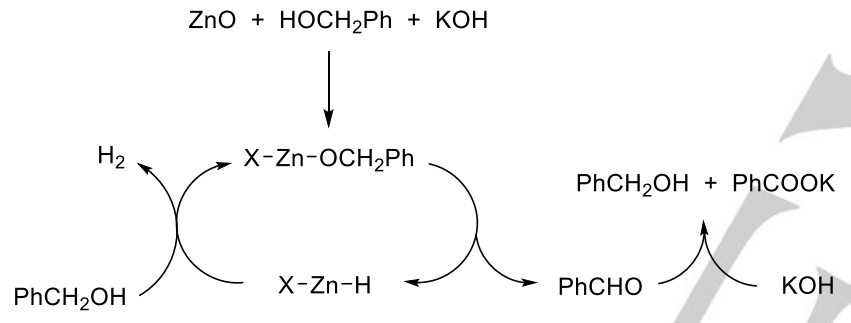

Scheme 2. Proposed mechanism.

In the case of benzaldehyde, the liberated aldehyde can undergo a Cannizzaro reaction with hydroxide to afford a 1:1 mixture of the carboxylate and the alcohol. We have previously shown that the Cannizzaro reaction occurs easily under these conditions. ${ }^{[13 \mathrm{~d}]}$ This was also confirmed when a mixture of benzaldehyde, potassium hydroxide and zinc oxide was heated to reflux in mesitylene. Complete conversion of benzaldehyde was observed after only $30 \mathrm{~min}$ and an almost equal mixture of benzoic acid (55\%) and benzyl alcohol (43\%) was formed. With aliphatic alcohols the Tishchenko reaction can account for the further oxidation to the carboxylic acid level. Several experiments were performed with heptanal, zinc oxide and potassium hydroxide, but even at slow addition only aldol condensation was observed. However, when heptan-1-ol was also included in the reaction, heptanoic acid was now obtained which is presumably due to a zinc alkoxide-mediated Tishchenko reaction followed by ester hydrolysis. In one experiment $1 \mathrm{mmol}$ of heptanal was added over $1 \mathrm{~h}$ to a mixture of zinc oxide, potassium hydroxide and $1 \mathrm{mmol}$ of heptan-1-ol in refluxing mesitylene followed by heating for an additional $1 \mathrm{~h}$. This gave complete conversion of the alcohol and the aldehyde and produced $1 \mathrm{mmol}$ of heptanoic acid together with several aldol products especially 2-pentylnon-2-en-1-ol. The large amount of acid after only $2 \mathrm{~h}$ cannot be formed from the alcohol alone, but shows the involvement of a further reaction from the aldehyde. The intermediate ester, although, could not be detected under these conditions and is presumably hydrolyzed rapidly. It is beyond the scope of this study to discuss the mechanism of the Tishchenko reaction in detail, but it should be noted that this transformation in some cases is accelerated by the presence of an alcohol where a bifunctional pathway with the formation of a metal hydride may be involved. ${ }^{29 a, 30]}$

\section{Conclusions}

In summary, zinc oxide has been developed as a catalyst for the acceptorless dehydrogenation of primary alcohols into carboxylic acids. The transformation can be applied to both benzylic and aliphatic alcohols where the former reacts faster than the latter. The catalytically active species is homogeneous and is believed to be the corresponding zinc alkoxide. Degradation of the alkoxide into the aldehyde was confirmed experimentally and explains the dehydrogenation with the release of hydrogen gas. The aldehyde can then undergo a disproportionation by either a Cannizzaro reaction or a Tishchenko reaction to afford a mixture of the carboxylic acid and the starting alcohol in the presence of hydroxide.

\section{Experimental Section}

General procedure for carboxylic acid synthesis: Zinc oxide $(32.60$ $\mathrm{mg}, 0.4 \mathrm{mmol}$ ) and potassium hydroxide $(224.4 \mathrm{mg}, 4 \mathrm{mmol})$ were placed in an oven-dried tube, which was placed in a Radley carousel. The flask was subjected to vacuum and then filled with nitrogen gas (repeated three times). Vacuum was applied again and the carousel heated to $170{ }^{\circ} \mathrm{C}$ for $1 \mathrm{~h}$. Subsequently, the tube was refilled with nitrogen gas. Anhydrous and degassed mesitylene $(3 \mathrm{~mL})$ was added and the mixture heated to reflux. Alcohol $(2 \mathrm{mmol})$ and tetradecane $(0.1 \mathrm{~mL}$ as internal standard) were added by syringe, and the reaction was refluxed with stirring under a flow of nitrogen for $18 \mathrm{~h}$ (benzylic alcohols) or $36 \mathrm{~h}$ (aliphatic alcohols). The mixture was cooled to room temperature and diethyl ether $(5 \mathrm{~mL})$ was added. The white precipitate was filtered off and washed with diethyl ether $(10 \mathrm{~mL})$. The precipitate was dissolved in water $(5 \mathrm{~mL})$ and acidified to $\mathrm{pH} 1$ with $16 \%$ aqueous hydrochloric acid. The aqueous layer was extracted with ethyl acetate $(3 \times 10 \mathrm{~mL})$. The combined organic layers were dried over sodium sulfate and concentrated in vacuo to give the corresponding acid as a pure compound.

\section{Acknowledgements}

The project was supported by the Villum Fonden (grant 12380). We thank Cecilie Hauberg Hansen for her assistance in performing the substrate scope study in Table 1. 
Keywords: alcohols • carboxylic acids • dehydrogenation • synthetic methods $\cdot$ zinc

[1] a) A. Corma, J. Navas, M. J. Sabater, Chem. Rev. 2018, 118, 1410 1459; b) C. Gunanathan, D. Milstein, Science 2013, 341, 1229712; c) S. Bähn, S. Imm, L. Neubert, M. Zhang, H. Neumann, M. Beller, ChemCatChem 2011, 3, 1853-1864; d) Y. Obora, Y. Ishii, Synlett 2011 30-51; e) R. Yamaguchi, K. Fujita, M. Zhu, Heterocycles 2010, 81 , 1093-1140; f) A. J. A. Watson, J. M. J. Williams, Science 2010, 329 635-636; g) G. E. Dobereiner, R. H. Crabtree, Chem. Rev. 2010, 110, 681-703.

[2] a) G. A. Filonenko, R. van Putten, E. J. M. Hensen, E. A. Pidko, Chem Soc. Rev. 2018, 47, 1459-1483; b) F. Kallmeier, R. Kempe, Angew. Chem. Int. Ed. 2018, 57, 46-60; Angew. Chem. 2018, 130, 48-63; c) B. Maji, M. K. Barman, Synthesis 2017, 49, 3377-3393; d) M. Garbe, K. Junge, M. Beller, Eur. J. Org. Chem. 2017, 4344-4362; e) E. Balaraman, A. Nandakumar, G. Jaiswal, M. K. Sahoo, Catal. Sci. Technol. 2017, 7, 3177-3195.

[3] For recent examples, see: a) K. Azizi, R. Madsen, ChemCatChem 2018, 10, 3703-3708; b) J. Das, D. Banerjee, J. Org. Chem. 2018, 83, 3378-3384; c) S. Parua, R. Sikari, S. Sinha, S. Das, G. Chakraborty, N. D. Paul, Org. Biomol. Chem. 2018, 16, 274-284; d) D.-W. Tan, H.-X. Li, D.-L. Zhu, H.-Y. Li, D. J. Young, J.-L. Yao, J.-P. Lang, Org. Lett. 2018 20, 608-611; e) T. T. Dang, A. M. Seayad, Chem. Asian J. 2017, 12, 2383-2387.

[4] a) S. Enthaler, ACS Catal. 2013, 3, 150-158; b) X.-F. Wu, Chem. Asian J. 2012, 7, 2502-2509.

[5] a) W. Sattler, S. Ruccolo, M. R. Chaijan, T. N. Allah, G. Parkin, Organometallics 2015, 34, 4717-4731; b) O. O. Kovalenko, $\mathrm{H}$ Adolfsson, Chem. Eur. J. 2015, 21, 2785-2788; c) G. Ding, B. Lu, Y. Li, J. Wan, Z. Zhang, X. Xie, Adv. Synth. Catal. 2015, 357, 1013-1021; d) S. Das, D. Addis, K. Junge, M. Beller, Chem. Eur. J. 2011, 17, 12186-12192; e) S. Das, K. Möller, K. Junge, M. Beller, Chem. Eur. J. 2011, 17, 7414-7417.

[6] a) P. Jochmann, D. W. Stephan, Chem. Eur. J. 2014, 20, 8370-8378; b) S. Werkmeister, S. Fleischer, K. Junge, M. Beller, Chem. Asian J. 2012, 7, 2562-2568; c) S. Werkmeister, S. Fleischer, S. Zhou, K. Junge, M. Beller, ChemSusChem 2012, 5, 777-782.

[7] a) A.-K. Wiegand, A. Rit, J. Okuda, Coord. Chem. Rev. 2016, 314, 71-82; b) K. Y. Zhizhin, N. N. Mal'tseva, G. A. Buzanov, N. T. Kuznetsov, Russ. J. Inorg. Chem. 2014, 59, 1665-1678.

[8] a) T. Tsuchimoto, H. Utsugi, T. Sugiura, S. Horio, Adv. Synth. Catal. 2015, 357, 77-82; b) T. Tsuchimoto, M. Fujii, Y. Iketani, M. Sekine, Adv. Synth. Catal. 2012, 354, 2959-2964.

[9] T. Tsuchimoto, Y. Iketani, M. Sekine, Chem. Eur. J. 2012, 18, 9500-9504.

[10] a) L. Saad, M. Riad, J. Serb. Chem. Soc. 2008, 73, 997-1009; b) M. Gliński, J. Kijeński, B. Sitarska, React. Kinet. Catal. Lett. 1998, 64, 275-279; c) V. K. Raizada, V. S. Tripathi, D. Lal, G. S. Singh, C. D. Dwivedi, A. K. Sen, J. Chem. Technol. Biotechnol. 1993, 56, 265-270.

[11] H. Nishino, H. Maruyama, M. Masuda (Kishimoto Sangyo Co., Ltd.), US 3957838, 1976.
[12] a) A. M. P. Koskinen, A. O. Kataja, Org. React. 2015, 86, 105-409; b) T. Seki, T. Nakajo, M. Onaka, Chem. Lett. 2006, 35, 824-829.

[13] a) E. W. Dahl, T. Louis-Goff, N. K. Szymczak, Chem. Commun. 2017 53, 2287-2289; b) A. Sarbajna, I. Dutta, P. Daw, S. Dinda, S. M. W Rahaman, A. Sarkar, J. K. Bera, ACS Catal. 2017, 7, 2786-2790; c) Z. Dai, Q. Luo, X. Meng, R. Li, J. Zhang, T. Peng, J. Organomet. Chem 2017, 830, 11-18; d) C. Santilli, I. S. Makarov, P. Fristrup, R. Madsen, J. Org. Chem. 2016, 81, 9931-9938; e) D. Ventura-Espinosa, C. Vicent, M. Baya, J. A. Mata, Catal. Sci. Technol. 2016, 6, 8024-8035; f) L. Zhang, D. H. Nguyen, G. Raffa, X. Trivelli, F. Capet, S. Desset, S. Paul, F. Dumeignil, R. M. Gauvin, ChemSusChem 2016, 9, 1413-1423; g) J. Malineni, H. Keul, M. Möller, Dalton Trans. 2015, 44, 17409-17414; h) J.-H. Choi, L. E. Heim, M. Ahrens, M. H. G. Prechtl, Dalton Trans. 2014, 43, 17248-17254; i) P. Sponholz, D. Mellmann, C. Cordes, P. G. Alsabeh, B. Li, Y. Li, M. Nielsen, H. Junge, P. Dixneuf, M. Beller, ChemSusChem 2014, 7, 2419-2422; j) E. Balaraman, E. Khashin, G. Leitus, D. Milstein, Nat. Chem. 2013, 5, 122-125.

[14] a) V. Cherepakhin, T. J. Williams, ACS Catal. 2018, 8, 3754-3763; b) K. Fujita, R. Tamura, Y. Tanaka, M. Yoshida, M. Onoda, R. Yamaguchi, ACS Catal. 2017, 7, 7226-7230.

[15] Y. Sawama, K. Morita, S. Asai, M. Kozawa, S. Tadokoro, J. Nakajima, Y. Monguchi, H. Sajiki, Adv. Synth. Catal. 2015, 357, 1205-1210.

[16] X. Wang, C. Wang, Y. Liu, J. Xiao, Green Chem. 2016, 18, 4605-4610.

[17] H. G. Ghalehshahi, R. Madsen, Chem. Eur. J. 2017, 23, 11920-11926.

[18] Z. Dai, Q. Luo, H. Jiang, Q. Luo, H. Li, J. Zhang, T. Peng, Catal. Sci. Technol. 2017, 7, 2506-2511.

[19] G. Tojo, M. Fernández, Oxidation of Primary Alcohols to Carboxylic Acids: A Guide to Current Common Practice, Springer, 2007.

[20] I. S. Makarov, R. Madsen, J. Org. Chem. 2013, 78, 6593-6598.

[21] S.-J. Chen, L.-H. Li, X.-T. Chen, Z. Xue, J.-M. Hong, X.-Z. You, J. Crystal Growth 2003, 252, 184-189.

[22] a) D. Gabriëls, W. Y. Hernández, B. Sels, P. Van Der Voort, A. Verberckmoes, Catal. Sci. Technol. 2015, 5, 3876-3902; b) J. T. Kozlowski, R. J. Davis, ACS Catal. 2013, 3, 1588-1600.

[23] For our recent analysis of trace metals in manganese-catalyzed reactions, see: C. Santilli, S. S. Beigbaghlou, A. Ahlburg, G. Antonacci, P. Fristrup, P.-O. Norrby, R. Madsen, Eur. J. Org. Chem. 2017 5269-5274.

[24] a) K. C. Waugh, M. Bowker, R. W. Petts, H. D. Vandervell, J. O’Malley, Appl. Catal. 1986, 25, 121-128; b) O. Koga, T. Onishi, K. Tamaru, J. Chem. Soc. Faraday / 1980, 76, 19-29.

[25] H. Brombacher, H. Vahrenkamp, Inorg. Chem. 2004, 43, 6042-6049.

[26] A. Dolega, Coord. Chem. Rev. 2010, 254, 916-937.

[27] M. Miyagawa, T. Akiyama, Chem. Lett. 2018, 47, 78-81.

[28] N. A. Bell, A. L. Kassyk, J. Organomet. Chem. 1988, 345, 245-251.

[29] a) S. A. Morris, D. G. Gusev, Angew. Chem. Int. Ed. 2017, 56, 6228-6231; Angew. Chem. 2017, 129, 6324-6327; b) D. G. Gusev ACS Catal. 2016, 6, 6967-6981; c) W. Baratta, S. Baldino, M. J. Calhorda, P. J. Costa, G. Esposito, E. Herdtweck, S. Magnolia, C. Mealli, A. Messaoudi, S. A. Mason, L. F. Veiros, Chem. Eur. J. 2014, 20 , 13603-13617; d) D. E. Prokopchuk, R. H. Morris, Organometallics 2012, 31, 7375-7385.

[30] D. G. Gusev, D. M. Spasyuk, ACS Catal. 2018, 8, 6851-6861. 
Entry for the Table of Contents (Please choose one layout)

Layout 1:

\section{FULL PAPER}

Text for Table of Contents

Layout 2:

\section{FULL PAPER}

Author(s), Corresponding Author(s)*

Page No. - Page No.

Title

((Insert TOC Graphic here: $\max$. width: $5.5 \mathrm{~cm}$; max. height: $5.0 \mathrm{~cm})$ )

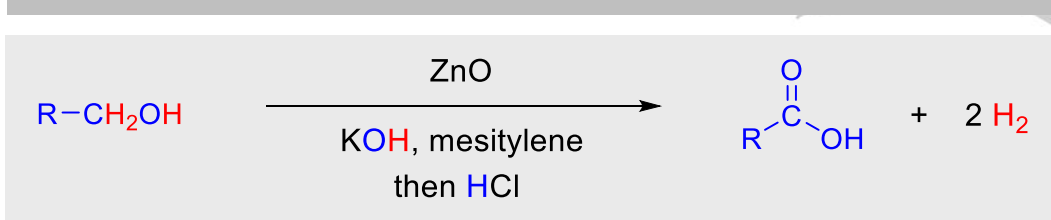

Catalysis at a bargain: Zinc oxide catalyzes the dehydrogenation of primary alcohols into carboxylic acids with the release of hydrogen gas. It constitutes the most inexpensive catalyst for the acceptorless alcohol dehydrogenation in solution where the catalytically active species most likely is a zinc alkoxide.
F. Monda, R. Madsen*

Page No. - Page No.

Zinc Oxide-Catalyzed Dehydrogenation of Primary Alcohols into Carboxylic Acids 